REVIEW ARTICLE

\title{
THE IMPACT OF THE COVID-19 PANDEMIC ON MANAGEMENT OF GASTROINTESTINAL MALIGNANCIES; A NARRATIVE REVIEW
}

\author{
Maha Imran, Muhammad Imran Anwar, Haroon Javaid Majid, Ahmad Naseer, Muhammad Aamir Jameel, Ayesha Humanyun \\ Shaikh Zayed Hospital, Lahore Pakistan
}

\begin{abstract}
The advent of the COVID-19 pandemic has led to widespread disruptions in the delivery of all essential and non-essential health care globally, with individuals afflicted with cancer representing a particularly vulnerable sub set of those affected. This article reviews the published literature and guidelines on the management of gastrointestinal malignancies during the COVID-19 pandemic worldwide and summarizes the challenges posed, innovations made and outcomes of the various screening, diagnostic and therapeutic modalities employed during the period from March to December 2020.
\end{abstract}

Keywords: COVID-19, Gastrointestinal cancers, Pandemic.

How to Cite This Article: Imran M, Anwar MI, Majid HJ, Naseer A, Jameel MA, Humanyun A. The Impact of the COVID-19 Pandemic on Management of Gastrointestinal Malignancies; A Narrative Review. Pak Armed Forces Med J 2021; 71(5): 1897-1902. doi:https://doi.org/10.51253/pafmj.v71i5.6777

This is an Open Access article distributed under the terms of the Creative Commons Attribution License (https://creativecommons.org/licenses/by-nc/4.0/), which permits unrestricted use, distribution, and reproduction in any medium, provided the original work is properly cited.

\section{INTRODUCTION}

Since its humble beginnings as a virus causing pneumonia of unknown origin, in Wuhan in December 2019 to being declared a pandemic on 11 March 2020, the Corona Virus Disease-19 (COVID-19) has wreaked ha-voc on the global health care infrastructure with over 61.8 million cases reported worldwide and 1.4 million individuals having succumbed to the illness as of December 2020.1 The earliest reports emerging from China identified cancer patients as being two times more susceptible to the acquisition of the virus and to suffering from a more severe course of the disease likely in part due to concurrent immunosuppression from the tumor and its treatment. ${ }^{2}$

Gastrointestinal tract malignancies including colorectal and esophagogastric tumors are amongst the most prevalent cancers worldwide and accounted for approximately $22.6 \%$ of all deaths due to cancer in $2020 .^{3}$ The ubiquitous interruption in the delivery of time sensitive oncological care, due to institution of lockdowns and social distancing protocols, reallocation of health care personnel and equipment towards curbing the spread of the pandemic and patient reluctance to seek medical care due to fears of contracting the virus has led to the emergence of a public health dilemma world over namely one of missed diagnoses and delayed presentations with subsequent adverse effects on outcomes of patients afflicted with GI tract cancers. ${ }^{4,5}$ A conservative estimate of the impact on mortality

Correspondence: Dr Maha Imran, Department of General Surgery, Shaikh Zayed Hospital, Lahore Pakistan

Received: 01 Jun 2021; revision received: 05 Jul 2021; accepted: 07 Jul 2021 from colorectal and breast cancers directly attributable to screening and diagnostic delays incurred as a consequence of the COVID-19 pandemic suggests almost 10,000 additional deaths in the United States over the next decade from these cancer types only. ${ }^{5}$ A retrospective cohort study conducted in Wuhan in the early stages of the pandemic revealed a worsening of the lymph node stage of patients suffering from colorectal (CRC) and gastric cancers due to a 2 month delay from initial diagnosis to subsequent presentation. ${ }^{6}$

Gastrointestinal (GI) malignancies have an insidious onset and presentation necessitating early diagnosis and intervention for improved long-term survival and decreased recurrence rates. The COVID19 pandemic has thrown into disarray the delivery of multi-disciplinary care to victims of these cancers, ${ }^{7}$ with the ramifications of this delay in management while not yet fully quantified are likely to be drastic and irreversible. ${ }^{8,9}$

The purpose of the present study was to highlight the impact that the COVID-19 pandemic has had on three principle facets of oncological care, predominantly screening, diagnosis and treatment and attempt to provide an arbitrary framework for cancer management, derived from the published literature and guidelines, in the uncertain terrain of a global health crisis such as posed by the COVID-19 pandemic.

\section{METHODOLOGY}

A narrative review was conducted to summarize the impact of the COVID-19 pandemic on the management of GI malignancies. A comprehensive search of the literature was carried out using the PUBMED data- 
base from March to December 2020. The keywords used were "gastrointestinal cancers" and "COVID-19". Filters applied included free full text and studies conducted in the English language only. The reference list of screened articles was reviewed and relevant studies that were missed on the initial search were identified and included in the review. Due to the heterogeneity of the obtained data, no attempt was made to pool the data or conduct a meta-analysis. A PRISMA flow chart was used to detail the selection process (Figure).

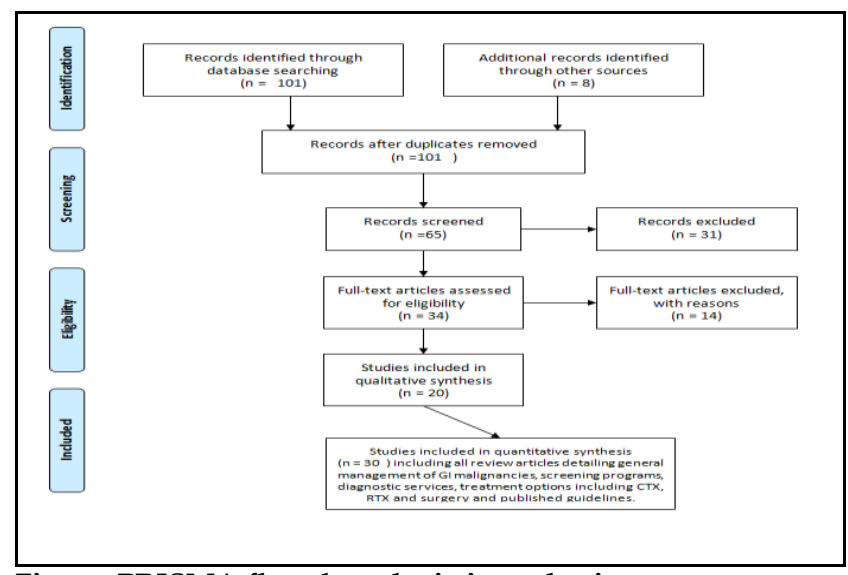

Figure: PRISMA flowchart depicting selection process.

\section{RESULTS}

\section{Impact on Screening}

Screening for colorectal cancer as a routine procedure, for individuals considered to be at risk for the development of this malignancy was largely suspended globally in resource replete countries where such programs are instituted as a basic health provision, in an attempt to mitigate the surge of patients afflicted with COVID-19 and to ameliorate the unprecedented burden on health care services. ${ }^{10-12}$ In the US suspension of all non-emergent endoscopic procedures saw CRC screening rates decline steeply to levels as low as $86 \%$ in comparison with the average rate before the onset of the pandemic, ${ }^{10}$ with $71 / 73$ (97\%) gastroenterology units in North America reporting a complete cessation of screening services. ${ }^{12}$ A less pronounced decline in screening colonoscopies was observed in Italy where a survey of 121 endoscopy departments revealed that $47 \%$ (49/105) of units had completely halted screening procedures during the peak of the pandemic. ${ }^{12}$ A retrospective controlled cohort study conducted in Italy during the first surge of the coronavirus pandemic demonstrated a 3.9 fold decline in the number of screening colonoscopies performed in a "COVID -free" hospital in the comparative study period from
March to May 2020 versus in 2019.13 The study did however, yield a favorable outlook for the continuation of CRC screening during the pandemic as stringent pre-procedural screening for symptoms of COVID-19, oropharyngeal swab testing and adherence to the use of personal protective equipment led to no members of the hospital staff or the patients testing positive for the disease. A population based study conducted in the Netherlands from January to October 2020 revealed that up to 6 weeks after the imposition of a moratorium on screening services the number of new cases of CRC amidst the targeted population was slightly lower than expected raising concerns regarding the number of missed diagnoses of colorectal cancers and the expected upsurge of patients presenting subsequently with stage migration of their disease. ${ }^{11}$

\section{Impact on Diagnosis}

Endoscopy forms the pinnacle on which rests the diagnosis of gastrointestinal tract malignancies. As services were globally halted in attempts to curb the rising spread of COVID-19, the percentage of diagnostic procedures fell to precipitously low levels, with the UK reporting endoscopic activity rates representing only $12 \%$ of pre pandemic levels during April and May $2020 .{ }^{14}$ Even after the resumption of routine endoscopic services these numbers did not see a significant upward trend owing to a multitude of reasons, predominantly the hesitancy exhibited by patients to seek health care owing to the perceived risk of acquiring a potentially deadly disease, the persistent reduction in resources and personnel and the need for enhanced sterilization and protective equipment. ${ }^{14}$ This disruption in routine diagnostic work caused potentially 2700 fewer diagnoses of cancer per week in the UK. ${ }^{14}$ TableI summarizes the barriers to care during the pandemic.

\begin{tabular}{l|c}
\multicolumn{2}{c}{ Table-I: Barriers to care during the COVID-19 pandemic. } \\
\hline Patient Factors & Health sector Factors \\
\hline Fear of contracting COVID-19 & $\begin{array}{c}\text { Reallocation of staff towards } \\
\text { pandemic control }\end{array}$ \\
\hline $\begin{array}{l}\text { Anxiety about a cancer } \\
\text { diagnosis and its implications }\end{array}$ & $\begin{array}{c}\text { Conversion of ICU beds and } \\
\text { operating theatres into COVID } \\
\text { designated facilities }\end{array}$ \\
\hline $\begin{array}{l}\text { Curbs on transportation } \\
\text { causing logistical impedance }\end{array}$ & $\begin{array}{c}\text { Limited availability of } \\
\text { personal protective equipment }\end{array}$ \\
\hline $\begin{array}{l}\text { Social isolation protocols } \\
\text { affecting care-giver } \\
\text { availability }\end{array}$ & $\begin{array}{c}\text { Increased sterilization } \\
\text { measures limiting number of } \\
\text { procedures performed daily }\end{array}$ \\
\hline $\begin{array}{l}\text { Cultural perception to avoid } \\
\text { burdening health facilities }\end{array}$ & $\begin{array}{c}\text { Risk of virus transmission due } \\
\text { to aerosol generating } \\
\text { procedures }\end{array}$ \\
\hline & $\begin{array}{c}\text { Lack of cohesive consensus } \\
\text { based practical guidelines }\end{array}$ \\
\hline
\end{tabular}




\section{COVID-19 Pandemic A Narrative Review}

A retrospective cohort study conducted in the UK aimed to quantify the impact of delays in diagnosis due to disruption of endoscopic facilities in terms of the increase in numbers of undiagnosed cases of gastric and esophageal cancers across various NHS trust hospitals. ${ }^{15}$ The study yielded an approximately $28 \%$ decline in the number of diagnostic procedures conducted across a comparable 4 month period from January to April in 2020 and 2019 with activity in April 2020 being $90 \%$ lower than in 2019. The resultant increase in the number of undiagnosed cases of gastric and esophageal cancers was estimated to be 750 with a larger proportion of the population presenting subsequently with advanced stage and potentially incurable disease. 15

A similar population based modeling study conducted in the UK attempted to highlight the detrimental effect of diagnostic delays on cancer outcomes vis-à-vis the survival and long term outlook of patients potentially suffering from colorectal and esophageal cancer. ${ }^{16}$ The study estimated an approximately $15.3-16.6 \%$ increase in avoidable cancer deaths from colorectal cancer and a $5.8-6 \%$ increase in preventable mortality in those afflicted by esophageal cancer up to 5 years after diagnosis. ${ }^{16}$ These are sobering figures considering that the unimpeded provision of time critical diagnostic facilities, which can detect these malignancies at a potentially curable stage thereby subverting their increased mortality, has been greatly affected by the ongoing battle against COVID-19.

A predictive population based study conducted in Hong Kong revealed a reduction of greater than 50\% in the volume of diagnostic endoscopies performed in the country during the COVID-19 pandemic with a decline of $38.1 \%$ and $49.1 \%$ in the number of patients newly diagnosed with gastric and colorectal cancer respectively. ${ }^{17}$ Using the Markov model the authors projected that due to delays incurred in diagnosis, approximately $4.6 \%$ of gastric and $6.4 \%$ of colorectal cancer patients would have stage migration of their disease at 6 months. ${ }^{17}$

\section{Impact on Treatment}

The increase in fatalities from COVID-19 paralleled the implementation of radical infection control and disease mitigation protocols with all elective oncological surgeries falling victim to complete cessation during the early surge of the pandemic. Initial guidelines by the various regulatory bodies including the American College of Surgeons, the Surgical Society of Oncology and the European Society for Medical Oncology called for the complete suspension of all non-emergency (bleeding, perforation, obstruction etc.) procedures for cancer surgeries with an emphasis towards neoadjuvant treatment modalities and endoscopic resection where amenable. ${ }^{4,18}$ Table-II summarizes the core recommendations of these varying guidelines.

A multicenter survey conducted across 79 GI and hepatopancreatobiliary (HPB) oncological surgery departments in 20 European countries revealed the implications the pandemic had on the surgical management of these malignancies with $59 \%$ of participants reporting that the pandemic had a very strong impact on the ongoing treatment of their patients with over $90 \%$ of respondents citing a decline in patient referrals since the onset of the virus outbreak. ${ }^{19} \mathrm{~A}$ one-third of the departments saw suspension of multidisciplinary tumor board meetings, and 39\% of surgeons working in the included hospitals reported postponement of all surgical procedures for GI and HPB cancers. The major deterrent reported by the participants included a paucity of resources predominantly operating rooms and ICU beds that had been reallocated towards pandemic control. ${ }^{19}$

While this may seem to represent a bleak picture especially pertaining to the prognosis of patients suffering from GI cancers in whom timely intervention is crucial in improving long terms outcome, reports from designated 'Cancer Hubs' that were set up to ensure unhampered oncological care were promising. A retrospective cohort study conducted at a tertiary care referral hospital in Piedmont, Italy a region hardest hit by the coronavirus pandemic assessed the outcomes of CRC surgery conducted during the peak of the pandemic. ${ }^{20}$ While overall general surgical procedures saw a decline of $56.3 \%$ from 2019 , the rate of oncological resection increased from $42.6 \%$ in 2019 to $59.5 \%$ in 2020 with a comparable post-operative complication rate of $20 \%$ in 2019 and $14.9 \%$ in 2020. Patients had a median hospital stay of 5 days in both cohorts and no patient or hospital staff acquired COVID-19. The authors advocated for continuation of oncological surgical practices that are evidence based instead of drastically altering treatment patterns, the repercussions of which will be felt only after the passage of a substantial amount of time. ${ }^{20}$

These results were echoed in a similar study conducted across a cancer designated hospital in Lombardy Italy which revealed that with adequate preoperative screening using nasopharyngeal swabs and chest CT scans patients could safely undergo elective 
surgical resections with no increased risk of perioperative mortality or virus transmission. ${ }^{21}$ Both these studies also negated the hypothesized increased risk of aerosolization with subsequent transmission of the coronavirus due to laparoscopic interventions. ${ }^{20,21}$

In the UK an analogous cancer Hub program was implemented where oncological care was executed uninterrupted in the background of the coronavirus pandemic. A retrospective cohort study conducted at a high volume tertiary trust hospital in Newcastle attempted to compare outcomes of management of esophagogastric cancer before and after the onset of the pandemic. ${ }^{22}$ In the study period from 12 March to 22 May 2020 a total of 191 patients were discussed in the Multi Disciplinary Team meeting (MDT) reflecting a $12 \%$ fall from pre pandemic days. Out of $80 \%$ of the patients received diagnostic, staging and treatment interventions that did not show any deviation from the preCOVID management pathway. Nineteen patients underwent surgical resection and twelve patients had endoscopic resection of their disease with no complications. Two patients developed COVID-19 but no mortality from the virus was reported. ${ }^{22}$ With esophagogastric tumors having an insidious onset, delays in presentation are associated with a significant upstaging of the disease rendering a potentially curative cancer, irresectable. This aimed to emphasize the need to continue delivery of cancer care to patients suffering from esophageal and gastric cancer within designated cancer hospitals, with meticulous attention being paid towards infection control protocols, pre-operative screening and multi-disciplinary coordination.

\section{DISCUSSION}

The COVID-19 pandemic has significantly altered the landscape of cancer management globally with the modifications implemented likely to cause reverberations that will echo long ahead in the years to come. The paucity of information regarding the transmission of the corona virus and the highly virulent nature of the pathogen necessitated the drastic measures undertaken during the peak of the pandemic in attempts to curb the rising spread of the disease and preserve valuable human life. However with the initiation of mass vaccination programs, judicious use of face masks and sanitization measures and observation of social distancing protocols the imminent threat now seems to stem from the repercussions of the delay in the definitive treatment of cancer patients as opposed to the hazards posed by the virus itself. The initial prudence exercised in the embryonic phases of the corona virus outbreak with the cessation of all non-essential health care services might have been the need of the hour but we are already beginning to observe the impact it has had on the short-term outcomes of patients with gastrointestinal malignancies. A systematic review conducted by Bhat et al, to assess the impact of delays in surgery

\begin{tabular}{|c|c|c|}
\hline $\begin{array}{l}\text { Cancer } \\
\text { Stage }\end{array}$ & $\begin{array}{c}\text { Upper } \\
\text { Gastrointestinal }\end{array}$ & $\begin{array}{c}\text { Lower } \\
\text { Gastrointestinal }\end{array}$ \\
\hline Early & $\begin{array}{c}\text { Endsoscopic resection } \\
\text { T1a-T1b }\end{array}$ & $\begin{array}{c}\text { Defer surgical } \\
\text { intervention }\end{array}$ \\
\hline $\begin{array}{l}\text { Locally } \\
\text { Advanced }\end{array}$ & $\begin{array}{l}\text { Neoadjuvant } \\
\text { chemotherapy }\end{array}$ & $\begin{array}{c}\text { Neoadjuvant } \\
\text { chemotherapy with } \\
\text { oral cepacitabine. } \\
\text { Rectal tumors: } \\
\text { short course RTX } \\
\text { > Long course CTX } \\
\end{array}$ \\
\hline $\begin{array}{l}\text { Emergency } \\
\text { presentation }\end{array}$ & $\begin{array}{c}\text { Endoscopic } \\
\text { intervention: gastric } \\
\text { outlet obstruction, } \\
\text { bleeding } \\
\text { Surgery: if failure of } \\
\text { endoscopy } \\
\end{array}$ & $\begin{array}{c}\text { Bleeding, } \\
\text { perforation, } \\
\text { obstruction; } \\
\text { perform diversion } \\
\text { or resection }\end{array}$ \\
\hline
\end{tabular}

on overall survival of patients afflicted with various GI malignancies revealed that postponing curative resection in patients afflicted with colonic carcinomas by as little as 5 weeks is associated with a lower survival. ${ }^{23}$ Similarly for rectal cancer delaying surgery for greater than 8 weeks after the administration of neoadjuvant treatment was found to be associated with worse outcomes and decreased overall survival. ${ }^{23}$ Concordantly, a studied conducted by the Mayo Clinic to quantify the loss of lives incurred from delayed resection of colonic cancer in the COVID era concluded that deferring definitive surgical treatment of patients afflicted with stage I to III colon cancers by 1 month was associated with a $25 \%$ increase in mortality in a 5 year follow up period versus a $37 \%$ increase when resection was delayed by 4 months. ${ }^{24}$

Gleaning insight from the centers where timely oncologic care was instituted to cancer patients during the pandemic the globe over, regulatory bodies and policy makers should be cognizant of the measures that can be put into effect to ensure continuing care to this sub set of the population. ${ }^{25}$ The use of personal protective equipment and face masks should be mandated for hospital staff and surgical teams, candidates for surgical resection should be encouraged to selfisolate for at least 2 weeks prior to their procedure and informed consent taken regarding the superimposed hazard of nosocomial transmission of the coronavirus 


\section{COVID-19 Pandemic A Narrative Review}

and its associated complications, all patients undergoing surgery should be tested pre operatively with a nasopharyngeal swab RT-PCR assay and CT thorax and routine COVID-19 screening of health care workers should be conducted to decrease the risk of disease propagation. ${ }^{24,26,27}$

The COVID-19 pandemic has provided oncologists with the opportunity to re imagine the current diagnostic and screening algorithms for gastrointestinal malignancies. Currently endoscopy remains the cornerstone for the diagnosis of GI cancers; however, a study conducted to assess the positivity ratio of CRC in patients with symptoms suspicious of the disease process revealed that only $1.7 \%$ of all individuals who underwent diagnostic colonoscopy were actually suffering from colonic carcinoma. ${ }^{28}$ With resumption of endoscopic services a huge upsurge of patients who had their screening or diagnostic tests delayed due to COVID induced suspensions is expected to overwhelm GI units. ${ }^{29}$ To deal with this overwhelming backlog, a system of triaging patients on the basis of their symptoms and positive fecal immunochemical test (FIT) should be implemented in attempts to ameliorate the burden on endoscopy units and decrease the risk of virus transmission. ${ }^{28}$ For individuals considered to be low risk colonoscopy should be deferred and alternative noninvasive diagnostic modalities such as the fecal immunochemical test, methylated septin 9 blood test and CT Colonoscopy can be used safely to rule out the presence of colonic malignancy. ${ }^{28,30}$

\section{CONCLUSION}

The COVID-19 pandemic has had an irrefutable impact on the management of GI malignancies; one that is yet to be fully quantified. While pontificating on the mistakes of yesterday it is pertinent to learn from them and going forward adopt the lessons learnt. The care of cancer patients should conform to evidence based practices which should not be substituted for oncologically inferior, hastily researched alternatives. With the majority of the countries continuing to battle surge after surge of COVID-19, regulatory bodies and policy makers need to ensure that time sensitive cancer diagnostic and management pathways be reinstituted rapidly and with scrupulous attention to infection control protocols to ensure the safety of both the patients and the health care providers.

\section{Conflict of Interest: None.}

\section{Authors' Contribution}

MI: Conception, design, analysis, data interpretation, MIA: Conception, design, analysis, data interpretation, HJM: Data analysis, AN: Data analysis, MAJ: Data analysis, AH: Data analysis, data interpretation.

\section{REFERENCES}

1. Organization WH. WHO Coronavirus Disease (COVID-19) Dashboard. (2020), [Internet] Available at: https://covid19.who. int. (Accessed on Dec 1, 2020)

2. Al-Shamsi HO, Alhazzani W, Alhuraiji A, Coomes EA, Chemaly $\mathrm{RF}$, Almuhanna $\mathrm{M}$, et al. A Practical approach to the management of cancer patients during the novel coronavirus disease 2019 (COVID-19) pandemic: an international collaborative group. Oncol 2020; 25(6): e936-e45.

3. International Agency for Research on Cancer. All cancers factsheet 2020, [Internet] Available from: https://gco.iarc.fr/ today/data/factsheets/cancers/39-All-cancers-fact-sheet.pdf. (Accessed on Dec 15, 2020)

4. Apostolou K, Vogli S, Frountzas M, Syllaios A, Tolia M, Papanikolaou IS, et al. Upper gastrointestinal cancer management in the COVID-19 era: risk of infection, adapted role of endoscopy, and potential treatment algorithm alterations. J Gastrointest Canc 2021; 52(2): 407-413.

5. Sharpless NE. COVID-19 and cancer. Sci 2020; 368(6497): 12901296.

6. Cai M, Wang G, Wu Y, Wang Z, Wang G, Tao K. Study of the gastrointestinal tumor progression during the COVID-19 epidemic in Wuhan. Br J Surg 2020; 107(11): e502-e503.

7. Verma AM, Nagpal JK. Gastrointestinal cancer pathways may breakdown due to COVID-19. Front Gastroenterol 2020; 11(5): 413-418.

8. Lai AG, Pasea L, Banerjee A, Hall G, Denaxas S, Chang WH, et al. Estimated impact of the COVID-19 pandemic on cancer services and excess 1-year mortality in people with cancer and multimorbidity: near real-time data on cancer care, cancer deaths and a population-based cohort study. BMJ Open 2020; 10(11): e043828

9. Morris EJA, Goldacre R, Spata E, Mafham M, Finan PJ, Shelton J, et al. Impact of the COVID-19 pandemic on the detection and management of colorectal cancer in England: a population-based study. Lancet Gastroenterol Hepatol 2021; 6(3): 199-208.

10. Shaukat A, Church T. Colorectal cancer screening in the USA in the wake of COVID-19. Lancet Gastroenterol Hepatol 2020; 5(8): 726-727.

11. Dinmohamed AG, Cellamare M, Visser O, de Munck L, Elferink MAG, Westenend PJ, et al. The impact of the temporary suspension of national cancer screening programmes due to the COVID19 epidemic on the diagnosis of breast and colorectal cancer in the Netherlands. J Hematol Oncol 2020; 13(1): 1-4.

12. Maida M. Screening of gastrointestinal cancers during COVID19: a new emergency. Lancet Oncol 2020; 21(7): e338-e342.

13. D'Ovidio V, Lucidi C, Bruno G, Lisi D, Miglioresi L, Bazuro ME. Impact of COVID-19 Pandemic on Colorectal Cancer Screening Program. Clin Colorectal Cancer 2021; 20(1): e5-e11.

14. Rees CJ, Rutter MD, Sharp L, Hayee B, East JE, Bhandari P, et al. COVID-19 as a barrier to attending for gastrointestinal endoscopy: weighing up the risks. Lancet Gastroenterol Hepatol 2020; 5(11): 960-962.

15. Markar SR, Clarke J, Kinross J. Practice patterns of diagnostic upper gastrointestinal endoscopy during the initial COVID-19 outbreak in England. Lancet Gastroenterol Hepatol 2020; 5(9): 804-805.

16. Maringe C, Spicer J, Morris M, Purushotham A, Nolte E, Sullivan $\mathrm{R}$, et al. The impact of the COVID-19 pandemic on cancer deaths due to delays in diagnosis in England, UK: a national, population-based, modelling study. Lancet Oncol 2020; 21(8): 10231034.

17. Lui TKL, Leung K, Guo CG, Tsui VWM, Wu JT, Leung W. Impacts of the coronavirus 2019 pandemic on gastrointestinal 


\section{COVID-19 Pandemic A Narrative Review}

endoscopy volume and diagnosis of gastric and colorectal cancers: a population-based study thomas. Gastroenterol 2020; 53(7): 1689-1699.

18. Society for Surgical Oncology. Society of Surgical Oncology (SSO) Resource for management options of GI and HPB cancers. 2020. Available from: https://www.surgonc.org/wp-content/ uploads/2020/04/GI-and-HPB-Resource-during-COVID-194.6.20.pdf.( Accessed on Dec 1, 2020)

19. Nevermann NF, Hillebrandt KH, Knitter S, Ritschl PV, Krenzien F, Benzing C, et al. COVID-19 pandemic: implications on the surgical treatment of gastrointestinal and hepatopancreatobiliary tumours in Europe. Br J Surg 2020; 107(9): e301-e302.

20. Allaix ME, Lo Secco G, Velluti F, De Paolis P, Arolfo S, Morino M. Colorectal surgery during the COVID-19 outbreak: do we need to change. Updates Surg 2021; 73(1): 173-177.

21. Carrano FM, Foppa C, Carvello M, Spinelli A. With adequate precautions colorectal cancer surgery can be safely continued during COVID-19 pandemic. Br J Surg 2020; 107(10): e417-e422.

22. Wahed S, Chmelo J, Navidi M, Hayes N, Phillips AW, Immanuel A. Delivering esophago-gastric cancer care during the COVID-19 pandemic in the United Kingdom: A surgical perspective. Dis Esophagus 2020; 33(9): 1-8.

23. Bhat PKR, Santosh Kumar KY, Sorake C, Kulamarva G. Gastrointestinal malignancies and the COVID-19 pandemic: evidencebased triage to surgery. J Gastrointest Surg 2020; 24(11): 26982699.
24. Larson DW, Abd El Aziz MA, Mandrekar JN. How many lives will delay of colon cancer surgery cost during the COVID-19 pandemic? an analysis based on the us national cancer database. Mayo Clin Proc 2020; 95(8): 1805-1807.

25. Richards M, Anderson M, Carter P, Ebert BL, Mossialos E. The impact of the COVID-19 pandemic on cancer care. Nat Cancer 2020; 1(6): 565-567.

26. Bhogal RH, Patel PH, Doran SLF, Zar S, Pollok JM, Jiao LR, et al. Approach to upper GastroIntestinal cancer surgery during the COVID-19 pandemic - Experience from a UK cancer centre. Eur J Surg Oncol 2020; 46(11): 2156-2157.

27. Shinde RS, Naik MD, Shinde SR, Bhandare MS, Chaudhari VA, Shrikhande SV, et al. To Do or Not to Do?-A Review of Cancer Surgery Triage Guidelines in COVID-19 Pandemic. Indian J Surg Oncol 2020; 11(2): 175-181.

28. Nunoo-Mensah JW, Giordano P, Chung-Faye G. COVID-19: An opportunity to reimagine colorectal cancer diagnostic testing a new paradigm shift. Clin Colorectal Cancer 2020; 19(4): 227230.

29. Gralnek IM, Hassan C, Dinis-Ribeiro M. COVID-19 and endoscopy: implications for healthcare and digestive cancer screening. Nat Rev Gastroenterol Hepatol 2020; 17(8): 444-446.

30. Arasaradnam RP, Bhala N, Evans C, Greenaway J, Logan R, Penman I, et al. Faecal immunochemical testing in the COVID-19 era: balancing risk and costs. Lancet Gastroenterol Hepatol 2020; 5(8): 717-719. 